\title{
Análise da vegetação secundária em unidades de conservação: o uso de recursos florestais por comunidades tradicionais
}

A florestas secundárias são fonte de recursos florestais para as populações tradicionais. Portanto, o objetivo do estudo é analisar a distribuição espacial da vegetação secundária na APA de Aramanaí e na comunidade de Maguari, na FLONA Tapajós, avaliando o potencial dessas áreas em fornecer espécies uteis, com destaque, a utilização de sementes florestais, para confecção de bijuterias pelos comunitários de Maguari. Foram realizadas entrevistas com os artesãos em Maguari, sobre a utilização de espécies florestais e posteriormente foi analisado a distribuição espacial dessa vegetação através do mapeamento do TerraClass, de uso e cobertura da terra dessas UCs. As principais espécies vegetais apontadas nas entrevistas foram o morototó (Schefflera morototoni (Aubl.) Maguire, Steyerm. \& Frodin), o tento vermelho (Ormosia arborea L. /Adenanthera pavonina L.), tento amarelo (Ormosia excelsa Beth), saboneteira (Sapindus saponaria L.), juta (Hymenaea courbaril L.), tucumã (Astrocaryum aculeatum G.F.W Meyer) e o caracaxá ou jupati (Raphia taedigera Mart.), destacando o morototó como a semente mais utilizadas por todos os entrevistados. Foi apontado, através do estudo de distribuição espacial, o agrupamento da população do morototó em áreas de vegetação secundárias, que corresponde cerca de $17 \%$ das duas UCs, demonstrando que a população da região utiliza as espécies uteis de áreas de vegetação secundária. A vegetação secundária se tornou uma fonte de recursos florestais paras as comunidades inseridas em UCs. Dessarte, é importante para economia das comunidades e ao mesmo tempo, promove a preservação da vegetação primária do desmatamento, sendo uma forma de conservar a floresta e o estoque de recursos para as gerações futuras.

\section{Analysis of secondary vegetation in protected areas: the use of forest resources by traditional communities}

\begin{abstract}
Secondary forests are a source of forest resources for traditional populations. Therefore, the objective of the study is to analyze the spatial distribution of secondary vegetation in Aramanaí EPA and in the Maguari community, in FLONA Tapajós, evaluating the potential of these areas to provide useful species, especially the use of forest seeds for confectioning. jewelry by Maguari community. Interviews were conducted with the artisans in Maguari about the use of forest species and the spatial distribution of this vegetation was then analyzed through the mapping of TerraClass, land use and land cover of these PAs. The main plant species mentioned in the interviews were the morototó (Schefflera morototoni (Aubl.) Maguire, Steyerm. \& Frodin), the red pepper (Ormosia arborea L. / Adenanthera pavonina L.), yellow pepper (Ormosia excelsa Beth), soap dish (Sapindus saponaria L.), jutei (Hymenaea courbaril L.), tucumã (Astrocaryum aculeatum GFW Meyer) and caracaxa or jupati (Raphia taedigera Mart.), Highlighting morototó as the seed most used by all interviewees. Through the spatial distribution study, it was pointed out the morototó population grouping in secondary vegetation areas, which corresponds to about $17 \%$ of the two UCs, demonstrating that the population of the region uses the useful species of secondary vegetation areas. Secondary vegetation has become a source of forest resources for communities within UCs. Thus, it is important for the economy of the communities and, at the same time, it promotes the preservation of the primary vegetation of deforestation, being a way to conserve the forest and the stock of resources for future generations.
\end{abstract}

Keywords: Traditional communities; Forest seeds; Schefllera morototoni; Flona Tapajós; APA Aramanaí.

Topic: Uso Sustentável da Biodiversidade

Reviewed anonymously in the process of blind peer.

Danielly Caroline Miléo Gonçalves (iD)

Universidade Federal do Oeste do Pará, Brasil

http://lattes.cnpq.br/5083066032365508

http://orcid.org/0000-0003-0521-115X

daniellycmg@gmail.com

Jéssica Ariana de Jesus Corrêa (iD

Universidade Federal do Oeste do Pará, Brasil

http://lattes.cnpq.br/718051090986748

http://orcid.org/0000-0002-2691-6020

jehssicorrea@yahoo.com.br

João Ricardo Vasconcellos Gama (id

Universidade Federal do Oeste do Pará, Brasil

http://lattes.cnpq.br/9058536716453750

http://orcid.org/0000-0002-3629-3437

irvgama@gmail.com

d

DOI: 10.6008/CBPC2318-2881.2019.001.0001
Received: 02/01/2019

Approved: 08/04/2019

Raimundo Cosme de Oliveira Júnior

Universidade Federal do Pará, Brasil

http://lattes.cnpq.br/6425044612146340

http://orcid.org/0000-0002-2735-1746

cosme@cpatu.embrapa.br

Referencing this:

GONÇALVES, D. C. M.; CORRÊA, J. A. J.; GAMA, J. R. V.; OLIVEIRA JÚNIOR, R. C.. Análise da vegetação secundária em unidades de conservação: o uso de recursos florestais por comunidades tradicionais. Nature and Conservation, v.12, n.1, p.1-9, 2019. DOI: http://doi.org/10.6008/CBPC2318-2881.2019.001.0001 


\section{INTRODUÇÃO}

A vegetação secundária ou capoeira é composta por arbórea-arbustiva, que se desenvolve secundariamente por meio da regeneração natural, após um distúrbio que elimina cerca de $90 \%$ da cobertura vegetal primária (BROWN et al., 1990; PEREIRA et al., 2001; MASSOCA et al., 2012). No contexto amazônico, as capoeiras podem ser definidas como áreas de crescimento espontâneo de vegetação secundária provenientes do processo de substituição dos ecossistemas florestais naturais por agroecossistemas (MASSOCA et al., 2012).

Os principais exemplos de ecossistemas de capoeira na região amazônica são as áreas de pousio no sistema agrícola de corte e queima e a vegetação formada após o abandono de área de pastagens degradadas. Também se pode observar a formação de áreas de capoeira após o abandono de cultivos agrícolas semiperenes e perenes. Estudos etnobotânicos (TOLEDO et al., 1995; CHAZDON et al., 1998) confirmam que as capoeiras também são fontes ricas de espécies úteis para as populações nativas e são intensamente usadas como fonte de produção de lenha, alimentos, remédios, corantes e material de construção, embora em geral, essas áreas secundárias sejam subavaliadas e pouco apreciadas, para fins comerciais e de manejo sustentado (PEREIRA et al., 2001).

A ocorrência de vegetação secundária foi documentada por muitos autores que mapearam áreas da Amazônia em escala local e encontraram relações desta com os ambientes físico e socioeconômico da região (ALVES et al., 2003; LU et al., 2003; ESPÍRITO-SANTO et al., 2005). Além disso, estimativas do total de área de vegetação secundária na Amazônia Legal foram realizadas pelo projeto mapeamento de Uso e Cobertura da Terra nas Áreas Desflorestadas da Amazônia Legal (TerraClass). Durante 10 anos de mapeamento foi verificado que houve um aumento das áreas de vegetação secundária na Amazônia Brasileira. Em 2004 a vegetação secundária correspondia a 16,4\% das áreas desmatadas, 21\% em 2008 (ALMEIDA et al., 2016) e 22,8\% em 2014 (EMBRAPA, 2016).

As florestas secundárias oferecem uma gama de produtos madeireiros e não madeireiros para as populações tradicionais da Amazônia (CORDEIRO et al., 2017). Através de conhecimentos herdados, extraem da natureza produtos de origem vegetal e animal para sua subsistência, tratamento de doenças, confecção de utensílios, ornamentos e também em rituais e magias, portanto, desenvolveram através da observação e da experimentação um extenso e minucioso conhecimento dos processos naturais e, até hoje, as únicas práticas de manejo adaptadas às florestas tropicais (MEGGERS, 1977; DESCOLA, 1990; POSEY et al., 1990; ARRUDA, 1999; SHANLEY et al., 2015). Desde as décadas de 1980 e 1990, os produtos extraídos da floresta (produtos florestais não madeireiros) são considerados uma solução para as populações tradicionais e redução da pobreza, sendo de baixo impacto ambiental, mantendo a conservação da floresta (STRAATMAN, 2014).

No sentido de preservação das florestas brasileiras foram criadas as Unidades de Conservação (UC) que delimitam e regulamentam o uso da terra dentro dessas áreas. Dentre as categorias de unidades de conservação criadas estão as unidades de conservação de Uso Sustentável, tais como, as Áreas de Proteção 
Ambiental (APA) e a Floresta Nacional (FN). As unidades de conservação buscam conciliar a presença humana nas áreas protegidas, por isso que as APAs e FN possuem certo grau de ocupação humana, porém cada tipo com suas peculiaridades de restrições (BRASIL, 2000).

Nas unidades de conservação, é restrita o uso da terra, sendo liberados áreas para plantios agrícolas de subsistência, a caça de animais e coletas de recursos naturais, portanto, esse comportamento pode influenciar no processo de formação de vegetação secundária, sendo assim, a floresta secundária é um elemento dominante e fundamental para a manutenção da agricultura e geração de renda, e portanto, tornase necessário mais conhecimento sobre formas de uso eficientes e sustentáveis (ALMEIDA et al., 2010).

Na APA de Aramanaí, assim como na comunidade de Maguari, na FLONA Tapajós, as populações residentes têm a vocação agrícola, cultivando pequenas plantações para sua subsistência. Porém, nos últimos anos, esse perfil tem mudado, com intensificação do turismo dessa região, tem aumentando o fluxo de pessoas com o intuito de conhecer o modo de vida local, sua cultura, além da beleza cênica local. Com isso, as populações tradicionais dessas áreas, passaram a perceber que seu modo de vida era um ponto de interesse desses turistas e passaram a produzir artesanatos e bijuterias com matéria-prima proveniente da floresta, que antes eram apenas feitos para seu próprio uso, hoje se tornou uma fonte de renda extras para essas famílias.

Portanto, o objetivo do trabalho é identificar as áreas de vegetação secundária na APA de Aramanaí e na comunidade de Maguari, na FLONA Tapajós, avaliando o potencial dessas áreas em fornecer espécies uteis, destacando as espécies florestais, como o Morototó (Schefflera morototoni (Aubl.) Maguire, Steyerm. \& Frodin), na utilização de sua semente para confecção de bijuterias pelos comunitários de Maguari.

\section{MATERIAS E MÉTODOS}

A área de estudo abrange a Área de Proteção Ambiental (APA) do Aramanaí e a porção norte da FLONA Tapajós localizadas no município de Belterra mesorregião do Baixo Amazonas, microrregião de Santarém (figura 1). As duas Unidades de conservação compreendem cerca de $70 \%$ da área total do Munícipio de Belterra. Por ser área de preservação de uso sustentável há uma dinâmica entre a floresta e as comunidades que estão inseridas dentro dessas áreas de preservação, sendo a floresta primária a maior proporção de uso e cobertura da terra (VIANA et al., 2009).

A APA do Aramanaí é uma unidade de conservação municipal criada em 2003 pela Lei no097, com área de 10.985 ha. É habitada por seis comunidades que são cortadas por mananciais e igarapés, onde vivem pescadores, agricultores familiares e comerciantes (bares e pousadas) que prestam serviço aos visitantes e turistas (VIANA et al., 2009).

A FLONA Tapajós foi criada pelo Decreto no73.684 de 19 de fevereiro de1974, sob jurisdição do IBDF (ITTO, 2004). Possui atualmente área de 527.319 hectares. Seus limites abrangem os municípios de Aveiro, Belterra, Placas e Rurópolis, no Oeste do Estado do Pará. Tem como objetivo o uso múltiplo sustentável dos recursos florestais e a pesquisa científica, com ênfase em métodos para exploração sustentável de florestas nativas (Lei 9.985/2000). A UC também apresenta expressiva riqueza sociocultural, representada por cerca 
de mil famílias e quatro mil moradores, distribuídas em 21 comunidades, três aldeias indígenas da etnia Munduruku (Bragança, Marituba e Takuara) e comunidades ao longo da BR-163 (lotes de assentados pelo INCRA). Em 2005 é realizado o Manejo Florestal Comunitário, realizado em uma área especialmente reservada para esse fim, sendo uma importante referência de uso sustentável da floresta (ICMBIO, 2017).

Além do Manejo Florestal destacam-se diversas iniciativas de uso sustentável com envolvimento comunitário, tais como: extração do látex, extração de óleos de andiroba e copaíba, produção do couro ecológico a partir do látex, bijuterias, móveis artesanais, comercialização de frutas in natura (açaí), produção de polpas e licores, produção de farinha, produção de mel, criação de peixes e turismo de base comunitária.

Nessas áreas estão compreendidas comunidades ribeirinhas, formada por pequenos núcleos familiares, tendo como fonte de renda o ecoturismo, crescente nos últimos anos, que impulsionou ainda mais a produção de borracha e coleta de sementes para a confecção de bijuterias e artesanato (SILVA et al., 2016). As comunidades ribeirinhas da APA de Aramanaí e porção norte da FLONA Tapajós têm bom acesso por terra ao município de Belterra, com estrada transitável durante todo o ano. Por isso, essas comunidades têm ampliado o cultivo de espécies florestais de uso econômico, como o plantio de seringueira, a exploração comercial de frutos (como o cupuaçu) e de óleos e sementes (IBAMA, 2004).

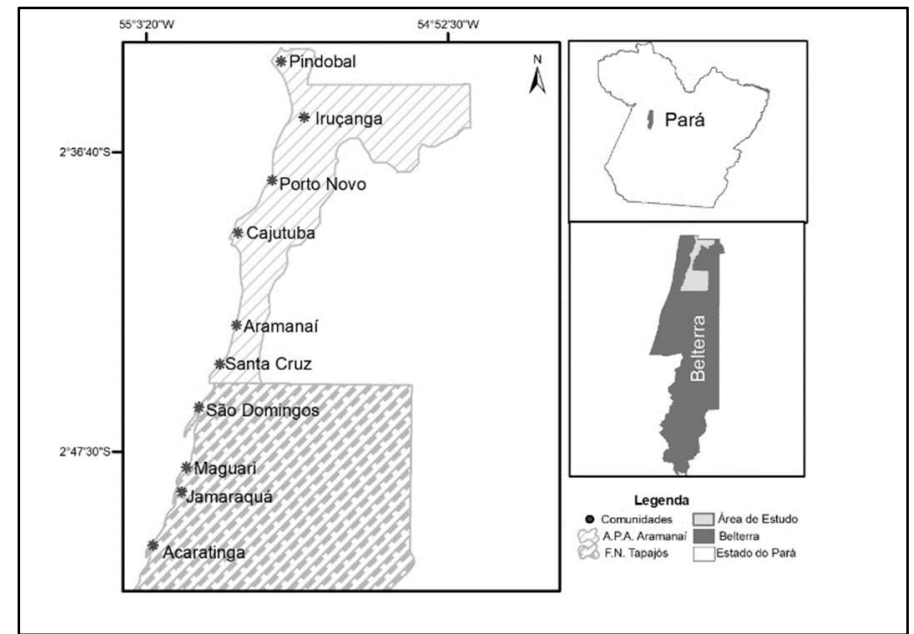

Figura 1: Localização da área de estudo (APA de Aramanaí em laranja e FLONA Tapajós em verde) no município de Belterra (PA) (vermelho).

A metodologia deste trabalho consistiu em duas etapas: a primeira consistiu no levantamento em uma das comunidades situadas na área de estudo para verificar quais tipos de recursos florestais são utilizados pela comunidade, sua utilidade; a segunda consistiu em mapear as áreas de vegetação secundária nas duas Unidades de Conservação.

A comunidade selecionada como estudo de caso foi a comunidade de Maguari situada na parte norte da FLONA Tapajós, tendo acesso fácil por terra, pelo município de Belterra, com estrada transitável durante todo o ano. É uma comunidade que vem ampliando o cultivo de espécies florestais de uso econômico, como o plantio de seringueira, a exploração comercial de frutos (como o cupuaçu) e de óleos (copaíba e andiroba) e sementes para fabricação de bijuterias e artesanatos, dentre as sementes estão o açaí, o morototó, a bacaba, o jutaí, a saboneteira, o tento vermelho e o tento amarelo (SILVA et al., 2016). Portanto, a partir da 
identificação do recurso florestal não madeireiro mais utilizado na comunidade foi realizado a caracterização da espécie.

Na comunidade de Maguari foram entrevistadas cinco famílias que trabalham com artesanato, sendo a matéria-prima proveniente da floresta próxima de suas residências. A pesquisa foi realizada através de questionários semiestruturados sobre as principais espécies coletadas, os produtos produzidos e o local de coleta. A entrevista foi realizada em outubro de 2016.

A segunda etapa, através do uso e cobertura da terra do mapeamento do TerraClass do ano de 2014, disponibilizado pelo Instituo Nacional de Pesquisas Espaciais (INPE) e Empresa Brasileira de Pesquisa Agropecuária (EMBRAPA), analisou a distribuição espacial da vegetação secundária nas Áreas de Proteção Aramanaí e na porção norte da FLONA Tapajós, bem como quantificou a área total compreendida por essa classe. Além disso, verificou-se a localização espacial de quatro unidades da espécie identificada nas entrevistas verificando em qual uso e cobertura da terra estava situada.

\section{RESULTADOS}

Foram apontadas pelas famílias entrevistadas da comunidade de Maguari as principais espécies de plantas utilizadas na elaboração de bijuterias e artesanatos (tabela 1). Dentre as mais citadas estão as sementes florestais de morototó (Schefflera morototoni (Aubl.) Maguire, Steyerm. \& Frodin), o tento vermelho (Ormosia arborea L./Adenanthera pavonina L.), tento amarelo (Ormosia excelsa Beth), saboneteira (Sapindus saponaria L.), jutaí (Hymenaea courbaril L.), tucumã (Astrocaryum aculeatum G.F.W Meyer) e o caracaxá ou jupati (Raphia taedigera Mart.). Todas são coletadas na comunidade ou foram domesticadas no quintal das residências dos comunitários, como é o caso da saboneteira.

Tabela 1: Produtos florestais não madeireiros coletados na comunidade de Maguari, FLONA do Tapajós, Município de Belterra (PA).

\begin{tabular}{|c|c|c|}
\hline Entrevistados & Espécies coletadas & Produtos fabricados \\
\hline Família 1 & $\begin{array}{l}\text { Sementes de saboneteira, morototó, tento vermelho, tento amarelo, tento vermelho } \\
\text { e preto, tucumã; } \\
\text { Palha de coqueiro e tucumã. }\end{array}$ & $\begin{array}{l}\text { Bijuterias (colares, } \\
\text { brincos, pulseiras); } \\
\text { Adornos (Tapetes e } \\
\text { leques). }\end{array}$ \\
\hline Família 2 & $\begin{array}{l}\text { Sementes de saboneteira, morototó, tento vermelho, tento amarelo, tento vermelho } \\
\text { e preto, jutaí; } \\
\text { Palha de coqueiro e tucumã. }\end{array}$ & $\begin{array}{l}\text { Bijuterias (colares, } \\
\text { brincos, pulseiras); }\end{array}$ \\
\hline Família 3 & Madeira de molongó, cedro vermelho. & $\begin{array}{l}\text { Animais decorativos de } \\
\text { madeira. }\end{array}$ \\
\hline Família 4 & $\begin{array}{l}\text { Sementes de saboneteira, morototó, tento vermelho, tento amarelo, tento vermelho } \\
\text { e preto, jutaí, jupati, olho de boi, olho de boto, crânio de macaco, piapixi } \\
\text { Látex da borracha (Manta de FHA) }\end{array}$ & $\begin{array}{l}\text { Bijuterias (colares, } \\
\text { brincos, pulseiras). }\end{array}$ \\
\hline Família 5 & $\begin{array}{l}\text { Sementes de morototó, tento vermelho, tento amarelo, jupati, seringa; } \\
\text { Palhas de tucumã. }\end{array}$ & $\begin{array}{l}\text { Bijuterias (colares, } \\
\text { brincos, pulseiras). }\end{array}$ \\
\hline
\end{tabular}

No presente estudo, a espécie mais citada pelos comunitários foi o morototó, com grande importância na confecção de bijuterias, especialmente na comunidade de Maguari, essa espécie é adaptada a diferentes tipologias florestais, sendo encontrada em florestas altas e densas de terra firme, capoeiras, capoeirões, margens de estradas e savanas, portanto, tem recebido diferentes classificações sucessionais desde espécie pioneira até clímax com exigência de luz; porém, apesar da ocorrência em floresta primária, 
desenvolve-se mais facilmente em floresta aberta, pouco densa e em vegetação secundária (CARVALHO, 2002; OHASHI et al., 2005; ANASTÁCIO et al., 2010).

A Figura 2a apresenta a distribuição espacial da vegetação secundária na área de estudo. É possível observar que está bem distribuída ao longo das unidades de uso sustentável. O uso da vegetação secundária em áreas de proteção ambiental, ainda é pouco documentada. No trabalho de Viana et al. (2009) sobre o desmatamento em áreas de unidades de conservação, afirma que a APA de Aramanaí sofre pressão do desmatamento do seu entorno, próximo as estradas, do avanço da agricultura mecanizada e das pastagens. A maior parte dessas áreas são ocupada por comunidades ribeirinhas que praticam agricultura de corte e queima e utilizam recursos das florestas (FERREIRA et al., 2005).

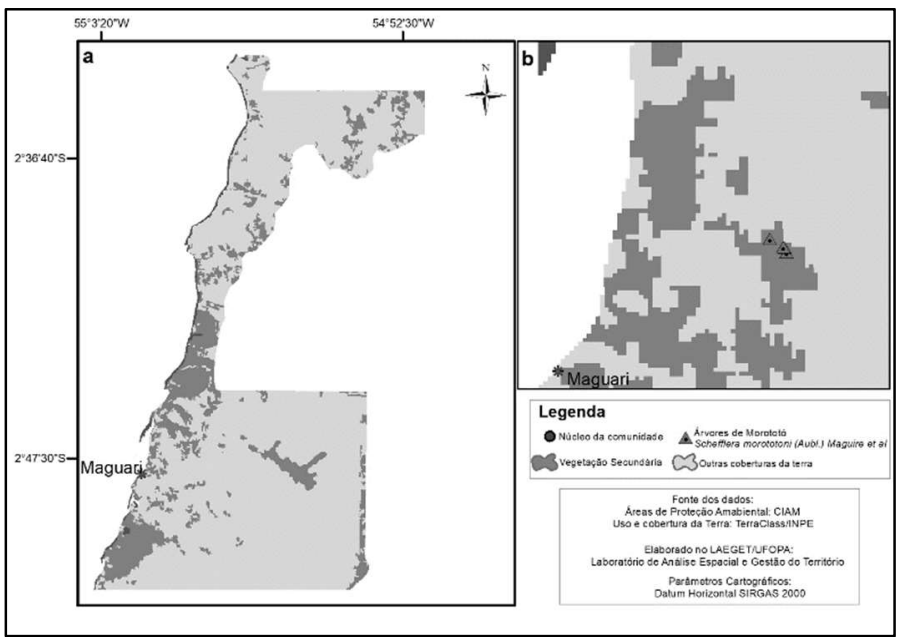

Figura 2: A: Distribuição espacial da vegetação secundária na APA de Aramanaí e FLONA Tapajós (comunidade Maguari); e B: Distribuição das árvores de morototó em áreas de floresta secundária na comunidade de Maguari, Município de Belterra (PA).

Sua distribuição espacial (figura 2b), na comunidade de Maguari aponta um agrupamento da população dessa espécie em áreas de vegetação secundárias, que corresponde cerca de $17 \%$ da vegetação das duas UCs (figura 3), demonstrando que a população da região utiliza as espécies uteis de áreas de vegetação secundária (CARIM et al., 2007). Essas áreas de vegetação secundária são próximas as residências ou áreas de plantio agrícola de subsistências dessas famílias (SILVA et al., 2014). Também próximo as residências dos artesãos, é feito o plantio de espécies florestais, como a saboneteira, para posterior uso na confecção de suas bijuterias (GONÇALVES et al., 2017).

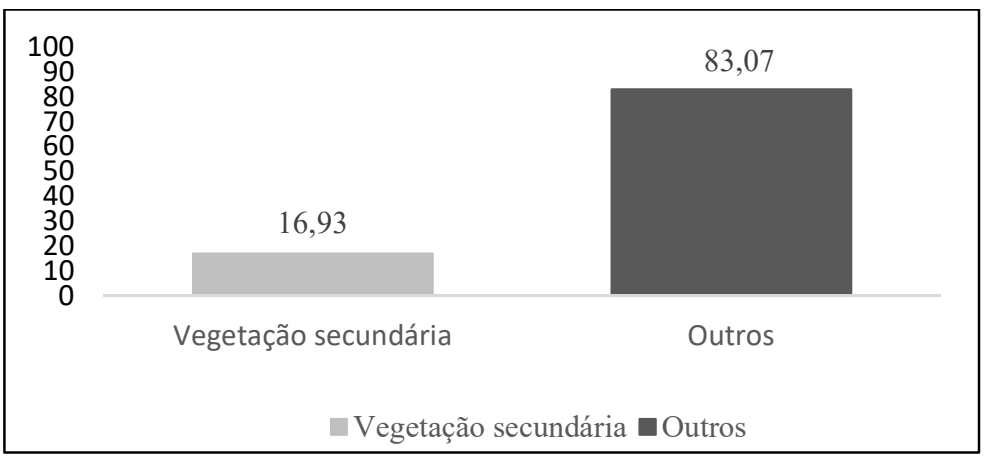

Figura 3: Porcentagem da vegetação secundária na APA de Aramanaí e FLONA Tapajós (comunidade Maguari) no Município de Belterra (PA). 
As áreas de vegetação secundária possuem potencial não madeireiro de grande relevância para as comunidades locais, contudo deve-se ressaltar a importância da conscientização do seu uso, bem como o manejo dessas áreas altamente explorada, correm o risco de esgotamento de algumas espécies devido à remoção contínua (GUALBERTO et al., 2014).

\section{DISCUSSÃO}

A maioria das espécies coletadas pelos comunitários são encontradas na floresta secundárias, como é o caso do morototó, tento vermelho e a saboneteira, e que por sua vez são as sementes mais usadas na produção de bijuterias. Por serem áreas mais próximas de suas residências, as espécies são facilmente acessíveis pelos comunitários que procuram as árvores já conhecidas por produzirem sementes boas na fabricação das bijuterias (SILVA et al., 2016).

A APA de Aramanaí e a FLONA Tapajós são áreas de proteção ambiental de uso sustentável, possuindo em sua maior parte, vegetação primária remanescentes, intercalada com manchas de vegetação secundária decorrente de atividades agrícolas e pecuária (RAYOL et al., 2011), essa última vem sendo destinada a atividades extrativas como coleta de sementes, fibras, madeiras para o artesanato e bijuterias. Essa atividade foi impulsionada pelo aumento do turismo dessa região, além das praias e das caminhadas nas florestas, os turistas procuram interagir com a comunidade e vivenciar as atividades executadas nela, com isso, os comunitários viram na confecção de artesanato e bijuteria uma forma mostrar sua cultura e ao mesmo tempo angariar uma renda extra para seu sustento (SHANLEY et al., 2015; SILVA et al., 2016).

Para Pereira et al. (2001), as áreas capoeiras podem continuar aumentando até se tornarem o ecossistema predominante na paisagem amazônica, exemplo citado pelos autores, foi da microrregião Bragantina, localizado ao norte do estado do Pará, que anterior, apresentava uma floresta tropical densa, e após 100 anos de colonização com atividades agrícolas restaram menos de 15\% de cobertura vegetal original e hoje as capoeiras ocupam cerca de $53 \%$ dessas áreas.

O uso da vegetação secundária em áreas de proteção ambiental, ainda é pouco documentada. No trabalho de Viana et al. (2009) sobre o desmatamento em áreas de unidades de conservação, afirma que a APA de Aramanaí sofre pressão do desmatamento do seu entorno, próximo as estradas, do avanço da agricultura mecanizada e das pastagens, ao contrário da APA Aramanaí, a taxa de desmatamento na FLONA do Tapajós foi inferior ao desmatamento observado no município de Belterra como um todo. A maior parte dessas áreas são ocupada por comunidades ribeirinhas que praticam agricultura de corte e queima e utilizam recursos da floresta (FERREIRA et al., 2005).

O bom manejo de espécies uteis, está relacionado ao conhecimento do ciclo de vida da espécie, o tipo de recursos produzidos, e de estrutura da população nas diferentes tipologias florestais (COSTA, 2012). O morototó, em especial, apresenta uma maior ocorrência em áreas de vegetação secundária, demostrando que essas florestas são importantes na obtenção de produtos florestais que se tornaram, como no caso de Maguari, uma fonte de renda para as famílias das comunidades. 


\section{CONCLUSÕES}

A vegetação secundária se tornou uma fonte de recursos florestais paras as comunidades inseridas em UCs. Na Comunidade de Maguari, tem áreas bem distribuição de vegetação secundária onde os moradores coletam sementes florestais para confecção de bijuterias e artesanato, se tornando uma fonte de renda para as famílias da comunidade. Enquanto que, na APA de Aramanaí, a vegetação secundária está mais limitada para o plantio agrícola, e pouca utilização dos recursos florestais. Os produtos provenientes das florestas são importantes para economia das comunidades e ao mesmo tempo, promove a preservação da vegetação primária do desmatamento, sendo uma forma de conservar a floresta e o estoque de recursos para as gerações futuras.

\section{REFERÊNCIAS}

ALMEIDA, C. A.; COUTINHO, A. C.; ESQUERDO, J. C. D. M.; ADAMI, M.; VENTURIERI, A.; DINIZ, C. G.; DESSAY, N.; DURIEUX, L.; GOMES, A. R.. High spatial resolution land use and land cover mapping of the Brazilian Legal Amazon in 2008 using Landsat-5/TM and MODIS data. Acta Amazonica, v.46, n.3, p.291-302, 2016.

ALMEIDA, C. A.; VALERIANO, D. M.; ESCADA, M. I. S.; RENNÓ, C. D.. Estimativa de área de vegetação secundária na Amazônia Legal Brasileira. Acta Amazonica, v.40, n.2, p.289302, 2010.

ALVES, D. S.; ESCADA, M. I. S.; PEREIRA, J. L. G.; LINHARES, C. A.. Land use intensification and in Rondônia, Brazilian Amazônia. International Journal of Remote Sensing, v.24, n.4, p.899-903, 2003

ARRUDA, R. S. V.. Populações tradicionais e a proteção dos recursos naturais. Ambiente $\&$ Sociedade, v.2, n.5, p.79-93, 1999.

BRASIL. Lei n.9985 de 18 de julho de 2000. Regulamenta o Art.225, §1으, incisos I, II, III e VII da Constituição Federal, institui o Sistema Nacional de Unidades de Conservação da Natureza. Brasília: DOU, 2000.

BROWN, S.; LUGO, A.. Tropical secondary forests. Journal of Tropical Ecology, v.6, p.1-32, 1990.

CARIM, S.; SCHWARTZ, G.; SILVA, M. F. F.. Riqueza de espécies, estrutura e composição florística de uma floresta secundária de 40 anos no leste da Amazônia. Acta Botanica Brasileira, v.21, n.2, p.293-308, 2007.

CARVALHO, P. E. R.. Mandiocão. Colombo: MAPA, 2002.

CHAZDON, R. L.; COE, F. G.. Abundance and diversity of useful species in second-growth, old-growth and selectivelogged forests of NE, Costa Rica. Série técnica: Reuniones Técnicas, n.4, p.165-190, 1998.

CORDEIRO, I. M. C. C.; RANGEL-VASCONCELOS, L. G. T.; SCHWARTZ, G.. O manejo da floresta secundária na Amazônia oriental. In: CORDEIRO.. Nordeste Paraense: panorama geral e uso sustentável das florestas secundárias, Belém: EDUFRA, 2017.
COSTA, C. B.. Prospecção, e viabilidade econômica para o manejo sustentável de Hymenaea spp. Dissertação (Mestrado em Ciência Florestal) - Universidade Federal de Viçosa, Viçosa, 2012.

DESCOLA, P.. Limites ecológicos e sociais do desenvolvimento da Amazônia. In: BOLOGNA, G.. Amazônia Adeus. Rio de Janeiro: Nova Fronteira, 1990.

EMBRAPA. Empresa Brasileira de Pesquisa Agropecuária. Terraclass 2004 a 2014: Dinâmica do uso e cobertura da terra no período de 10 anos nas áreas desflorestadas da Amazônia legal brasileira. Brasília: EMBRAPA, 2016.

ESPÍRITO-SANTO, F. D. B.; SHIMABUKURO, Y. E.; KUPLICH, T. M.. Mapping forest successional stages following deforestation in Brazilian Amazonia using multi-temporal Landsat images. International Journal of Remote Sensing, v.26, n.3, p.635-642, 2005.

FERREIRA, L. V.; VENTICINQUE, E.; ALMEIDA, S.. O desmatamento na Amazônia e a importância das áreas protegidas. Estudos Avançados, v.19, n.3, 2005.

GONÇALVES, D. C. M.; ALMEIDA, E. C.; ANDRADE, D. F. C.; GAMA, J. R. V.. Pesquisa científica voltada ao manejo de produtos florestais não madeireiros na FLONA do Tapajós. In: SEMINÁRIO DE PESQUISA DA FLORESTA NACIONAL DO TAPAJÓS E I SEMINÁRIO DA RESERVA EXTRATIVISTA TAPAJÓS ARAPIUNS, 3. Anais. Santarém: 2017.

GUALBERTO, M. L. C.; RIBEIRO, R. B. S.; GAMA, J. R. V.; VIEIRA, D. S.. Fitossociologia e potencial de espécies arbóreas em ecossistema sucessional na Floresta Nacional do Tapajós, Pará. Agroecossistemas, v.6, n.1, p.42-57, 2014.

IBAMA. Instituto Brasileiro do Meio Ambiente e dos Recursos Naturais Renováveis. A Floresta Nacional do Tapajós. Brasília: IBAMA, 2004.

ICMBIO. Instituto Chico Mendes de Conservação da Biodiversidade. A Floresta Nacional do Tapajós. Brasília: ICMBio 2017.

LU, D. S.; MAUSEL, P.; BRONDIZIO, E.; MORAN, E..

Classification of successional forest stages in the Brazilian 
Amazon basin. Forest Ecology and Management, v.181, n.3, p.301-312, 2003

MASSOCA, P. E.; JAKOVAC, A. C. C.; BENTOS, T. V.; WILLIAMSON, G. B.; MESQUITA, R. C. G.. Dinâmica e trajetórias da sucessão secundária na Amazônia Central. Boletim do Museu Paraense Emílio Goeldi, v.7, n.3, p.235250, 2012.

MAY, P.. Building institutions and markets for non-wood forest products from Brazilian Amazon. Unasylva, v.42, n.165, p.9-16, 1991.

MEGGERS, B.. Amazônia, a ilusão de um paraíso. Rio de Janeiro: Civilização Brasileira, 1977.

OHASHI, S. T.; LEÃO, N. V. M.. Morototó Schefflera morototoni (Aubl.) Maguire, Steyern. \& Frodin. Informativo Técnico Rede de Sementes da Amazônia, n.12, 2005.

PEREIRA, C. A.; VIEIRA, I. C. G.. A importância das florestas secundárias e os impactos de sua substituição por plantios mecanizados de grãos na Amazônia. Interciencia, v.26, n.8, 2001.

POSEY, D. A.; ANDERSON, A. B.. O reflorestamento indígena. In: BOLOGNA, G.. Amazônia Adeus. Rio de Janeiro: Nova Fronteira, 1990.

RAYOL, B. P.; ALVINO-RAYOL, F. O.; SILVA, M. F. F.. Similaridade florística entre o estrato arbóreo e a regeneração natural de uma floresta secundária, no município de Bragança, nordeste do estado do Pará, Brasil. Revista Brasileira de Agroecologia, v.6, n.3, p.107-114, 2011.

SANTANA, A. C.; SILVA, I. M.; OLIVEIRA, C. M.; SILVA, R. C.; FILGUEIRAS, G. C.; COSTA, A. D.; SOUZA, T. F.; HOMMA, A. K. O.. Caracterização do Mercado de produtos florestais madeireiros e não-madeireiros da Região Mamuru-

Arapiuns. Belém: Fundação de Apoio à Pesquisa, Extensão e Ensino em Ciências Agrárias, 2008.

SANTOS, A. J.; HILDEBRAND, E.; PACHECO, C. H. P.; PIRES, P. T. L.; ROCHADELLI, R.. Produtos Não Madeireiros: Conceituação, classificação, valoração e mercados. Revista Floresta, v.33, n.2, p.215-224, 2003.

SHANLEY, P.; PIERCE, A. R.; LAIRD, S. A.; BIMMQÜIST, C. L.; GUARIGUATA, M. R.. From Lifelines to Livelihoods: Nontimber Forest Products into the Twenty-First Century. In: Tropical Forestry Handbook, p.1-50, 2015.

SILVA, R. E.; BONFIM, F.; GARCIA, M. N.. Coletoras de sementes do Tapajós: mulheres, saberes práticos, relações de gênero e a floresta saberes práticos, relações de gênero e a floresta. Revista Vivência 43, v.43, p.85-95, 2014

SILVA, R. E.; SOUZA, R, R.; BONFIM, F. S.. A extração do látex e a coleta de sementes em comunidades da FLONA Tapajós: Bases empíricas para discussão da racionalidade ambiental. Gaia Scientia, v.10, n.1, p.126-132, 2016.

STRAATMANN, J.. Rede voltadas para produtos florestais não madeireiros: análise da influência de redes de cooperação nas cadeias de valor da Terra do Meio no Pará. Tese (Doutorado em Engenharia de Produção) Universidade de São Paulo, São Carlos, 2014.

TOLEDO, V. M.; BATIS, A. I.; BECERRA, R.; MARTÍNEZ, E.; RAMOS, C. H.. La selva útil: etnobotánica quantitativa de los grupos indígenas del trópico húmedo de México. Interciencia, v.20, p.177-187, 1995.

VIANA, J. S.; FONSECA, M. G.. Expansão de estradas e desmatamento em unidades de conservação do município de Belterra, Pará. In: SIMPÓSIO BRASILEIRO DE SENSORIAMENTO REMOTO, 14. Anais. Natal: INPE, 2009.

A CBPC - Companhia Brasileira de Produção Científica (CNPJ: 11.221.422/0001-03) detém os direitos materiais desta publicação. Os direitos referem-se à publicação do trabalho em qualquer parte do mundo, incluindo os direitos às renovações, expansões e disseminações da contribuição, bem como outros direitos subsidiários. Todos os trabalhos publicados eletronicamente poderão posteriormente ser publicados em coletâneas impressas sob coordenação da Sustenere Publishing, da Companhia Brasileira de Produção Científica e seus parceiros autorizados. Os (as) autores (as) preservam os direitos autorais, mas não têm permissão para a publicação da contribuição em outro meio, impresso ou digital, em português ou em tradução. 